\title{
Management of acute coronary occlusion during percutaneous transluminal coronary angioplasty: experience of complications in a hospital without on site facilities for cardiac surgery
}

\author{
S Geoffrey Richardson, Patricia Morton, J Gerard Murtagh, D Barry O'Keeffe, Philip Murphy, \\ Michael E Scott
}

\begin{abstract}
Objective-To determine whether percutaneous transluminal coronary angioplasty may be safely performed in cardiology centres in the United Kingdom without immediate on site cardiac surgical cover for complications arising at angioplasty.

Design-Retrospective review of coronary angioplasties and complications in a hospital without on site cardiac surgical cover.

Setting-All angioplasties were performed in the catheterisation laboratory of the Belfast City Hospital. Revascularisation surgery for complicated coronary angioplasty was performed in the cardiac surgical unit of the Royal Victoria Hospital, $2.4 \mathrm{~km}$ away from the catheterisation laboratory.

Patients-540 Coronary angioplasties were performed on 512 patients between late 1982 and November 1988. Indications included stable angina, unstable rest angina, and suitable coronary disease at coronary arteriography after myocardial
\end{abstract} infarction.

Main outcome measures-In hospital mortality after complicated coronary angioplasty and delay to surgical revascularisation after acute coronary occlusion at angioplasty.

Results-Coronary angioplasty was successful in 444 cases $(82 \%)$. Acute coronary occlusion occurred in 35 cases $(6 \cdot 5 \%)$. Twelve patients required urgent revascularisation surgery and were transferred safely to the surgical unit; none of these patients died. A mean delay of 268 minutes (range 180-390 minutes) occurred before revascularisation compared with 273 minutes (range 108-420 minutes) in the Royal Victoria Hospital, where on site surgical cover was available. The principal cause of delay was the wait for a cardiac operating theatre to become available and not the transfer time between hospitals. Five deaths occurred after coronary angioplasty, a mortality of $0.9 \%$. Three deaths were related to acute coronary occlusion. The absence of immediate surgical help did not influence the outcome in any patient.

Conclusion-With careful selection of patients coronary angioplasty may be safely performed in a hospital without on site cardiac surgical facilities, provided that these are available at a nearby centre.

\section{Introduction}

Coronary angioplasty is associated with a small risk of major complications, the most serious of which is abrupt total coronary occlusion. This usually results from dissection of the arterial wall and the creation of an occlusive intimal flap, which may be associated with the formation of intracoronary thrombus. Without a well developed collateral circulation myocardial infarction, haemodynamic deterioration, and even death may occur. The risk of these complications has led the subcommittee on coronary angioplasty of the American College of Cardiology and American Heart Association Task Force to state that the absence of a formal cardiac surgical programme within the institution is an absolute contradiction to coronary angioplasty.' Should its recommendations be applied in the United Kingdom, where many centres rely on off site cardiac surgical support for emergencies arising during coronary angioplasty? As yet there has not been a policy statement on this matter from cardiologists in the United Kingdom. We reviewed the experience of a moderately large angioplasty centre without on site facilities for cardiac surgery, the aim being to establish whether coronary angioplasty can safely be performed under these conditions.

\section{Patients and methods}

LOCAL GEOGRAPHY AND FACILITIES

Coronary angioplasty services for the Northern Ireland region are provided in two teaching hospitals in Belfast: the Belfast City and Royal Victoria Hospitals. All angioplasties discussed here were performed in the catheterisation laboratory of the Belfast City Hospital. Regional cardiac surgical facilities are based at the Royal Victoria Hospital site, which is situated $2.4 \mathrm{~km}$ from the Belfast City Hospital.

\section{CASE SELECTION}

Clinical indications for coronary angioplasty included stable effort induced angina, unstable angina with rest pain, myocardial infarction with postinfarction angina, and recent myocardial infarction treated with thrombolytic agents. Coronary angioplasty was performed if coronary arteriography confirmed the presence of one or more lesions with a stenosis of $>70 \%$ in diameter that were considered to be technically suitable for angioplasty.

\section{PROCEDURES}

Coronary angioplasties were discussed beforehand with a cardiac surgeon from the Royal Victoria Hospital. The surgeons agreed to provide emergency surgical cover in the event of a serious complication occurring at angioplasty, but they continued with their routine surgical caseload while angioplasties were being performed. An operating theatre was not kept in readiness for emergency surgery. Relevant information on patients, including blood grouping, was given to the surgical centre before angioplasty.

Coronary angioplasty was performed through the femoral artery using standard techniques. Its 
success was judged by angiographic appearances and monitoring of the translesion pressure gradient. A reduction in stenosis of $\geqslant 50 \%$ was considered to be a successful result. If coronary occlusion occurred during the procedure an attempt to reopen the artery was made with an intracoronary injection of glyceryl trinitrate and repeat balloon dilatation of the vessel. If this failed the patient was treated either by conventional medical methods or by urgent revascularisation surgery, depending on the severity of the developing myocardial infarction.

If cardiac surgery was required a cardiac surgeon was informed immediately by telephone. Transport was provided by the local ambulance service with a doctor, nurse, and physiological measurement technician in accompaniment. The patient was transferred directly to the cardiac operating theatre without the need for any form of admission procedure.

Records of all procedures were reviewed to determine the frequency of acute coronary occlusion occurring in association with coronary angioplasty. Outcome was examined with reference to the methods of management. Factors influencing the delay between coronary occlusion and cardiac surgery were examined and their importance assessed.

\section{Results}

From late September 1982 until mid-November 1988,540 coronary angioplasties were performed on 512 patients (single vessel $=491(91 \%)$, multivessel $=49$ $(9 \%))$. A successful result was achieved in 444 cases $(82 \%)$. Table I shows the increase in the number and success of coronary angioplasties over the six years.

Acute coronary occlusion occurred in 35 cases $(6.5 \%)$. The site of coronary occlusion was the main left anterior descending artery in 13 cases, the diagonal left anterior descending artery in two, the right coronary artery in 17 , and the left circumflex artery in three. Major arterial wall dissection extending beyond the confines of the coronary stenotic lesion was the mechanism of coronary occlusion in 15 cases. Less severe arterial dissection, identified by angiographic

TABLE I - Numbers of angioplasties performed from 1982 to 1988 with numbers (percentages) that were successful

\begin{tabular}{cccr}
\hline & \multicolumn{2}{c}{ Type of coronary disease } & \\
\cline { 2 - 3 } Year & Single vessel & Multivessel & Success \\
\hline 1982 & 5 & & $3(60)$ \\
1983 & 31 & 1 & $23(74)$ \\
1984 & 53 & 3 & $44(81)$ \\
1985 & 88 & 5 & $70(77)$ \\
1986 & 68 & 22 & $57(78)$ \\
1987 & 125 & 18 & $126(86)$ \\
1988 & 121 & 49 & $444(82)$ \\
\hline Total & 491 & & 440 \\
\hline
\end{tabular}

staining of the vessel intima, was associated with intraluminal filling defects and coronary occlusion in 14 cases. These defects were presumed to be intracoronary thrombus. Sustained coronary spasm was considered to be the cause of coronary occlusion in six cases.

Acute coronary occlusion occurred during coronary angioplasty in 32 patients. In three patients occlusion occurred after the procedure was completed-at two, eight, and 12 hours after angioplasty.

\section{MANAGEMENT OF OCCLUSION}

Eleven patients received urgent coronary bypass surgery after occlusion at coronary angioplasty (table II), seven being men and four women (mean age $=52.6$ years). Ten patients had single vessel coronary disease and one had double vessel disease. Mean left ventricular ejection fraction was $73 \%$ (range $61-80 \%$ ). The occluded artery was the left anterior descending in three cases and the right coronary artery in eight. Before transfer to the surgical unit two patients developed ventricular fibrillation, which was successfully corrected by cardioversion. Three patients required temporary transvenous cardiac pacing for serious bradycardia. Intra-aortic balloon counterpulsation was started in one patient with sustained hypotension and maintained during transfer to the surgical unit. The mean delay from the onset of coronary occlusion to revascularisation was 268 minutes (range 180-390 minutes). The cardiac surgical team also provided support for coronary angioplasty within their own institution. After complicated procedures in the Royal Victoria Hospital catheterisation laboratory the mean delay before revascularisation occurred was 273 minutes (range 108-420 minutes). None of the patients referred for urgent cardiac surgery died.

Acute coronary occlusion during angioplasty was successfully treated by repeat coronary dilatation in 12 patients. The occluded artery was the left anterior descending in seven cases and the right coronary artery in five. Temporary cardiac pacing for complete heart block was needed in one case. One patient died 10 days after coronary angioplasty (see below). Repeat angioplasty was also performed late in one patient who developed coronary occlusion two hours after initially successful dilatation of the left anterior descending artery. Systemic hypotension necessitated aortic balloon counterpulsation for 24 hours. This was followed by complete recovery. A total of 13 patients $(2.5 \%)$ had coronary patency restored by repeat coronary angioplasty. None of these patients died.

In 11 cases $(2 \cdot 0 \%)$ acute coronary occlusion was treated medically after unsuccessful attempts at redilatation (table III). In seven patients who developed occlusion at the time of angioplasty the area of myocardium at risk was judged to be small because of

TABLE II - Emergency surgery after coronary angioplasty in 12 patients

\begin{tabular}{|c|c|c|c|c|}
\hline $\begin{array}{l}\text { Case } \\
\text { No }\end{array}$ & $\begin{array}{l}\text { Type of } \\
\text { coronary } \\
\text { disease }\end{array}$ & $\begin{array}{l}\text { Occluded } \\
\text { artery }\end{array}$ & Emergency surgery & $\begin{array}{c}\text { Time from coronary } \\
\text { occlusion to revascularisation } \\
\text { (minutes) }\end{array}$ \\
\hline 1 & Single & Right coronary & Saphenous vein graft (right coronary artery) & 360 \\
\hline 2 & Single & Right coronary & Saphenous vein graft (right coronary artery) & 210 \\
\hline 3 & Single & Right coronary & Saphenous vein graft (right coronary artery) & 260 \\
\hline 4 & Single & Right coronary & Saphenous vein graft and endarterectomy (right coronary artery) & 295 \\
\hline 5 & Double & Left anterior descending & Saphenous vein graft (right coronary and left anterior descending arteries) & Uncertain \\
\hline 6 & Single & Right coronary & Saphenous vein graft (right coronary artery) & 390 \\
\hline 7 & Single & Right coronary & Saphenous vein graft (right coronary artery) & 255 \\
\hline 8 & Single & Left anterior descending & $\begin{array}{l}\text { Saphenous vein graft (left anterior descending and diagonal left anterior } \\
\text { descending arteries) }\end{array}$ & 300 \\
\hline 9 & Single & Right coronary & Saphenous vein graft (right coronary ar:ery) & 220 \\
\hline 10 & Single & Left anterior descending & $\begin{array}{l}\text { Saphenous vein graft and endarterectomy (left anterior descending and } \\
\text { diagonal left anterior descending arteries) }\end{array}$ & 180 \\
\hline 11 & Single & Right coronary & Saphenous vein graft (right coronary artery) & 240 \\
\hline 12 & Double & & Removal of wire from left anterior descending artery & $240 \dagger$ \\
\hline
\end{tabular}

* Single, double, or triple vessel coronary disease.

†Surgery performed to remove retained fragment of guide wire for coronary angioplasty; coronary occlusion did not occur. 


\begin{tabular}{|c|c|c|c|c|c|c|}
\hline $\begin{array}{c}\text { Case } \\
\text { No }\end{array}$ & $\begin{array}{l}\text { Occluded } \\
\text { artery }\end{array}$ & $\begin{array}{c}\text { Degree of } \\
\text { collateral } \\
\text { blood flow }\end{array}$ & $\begin{array}{l}\text { Mechanism of } \\
\text { arterial } \\
\text { occlusion }\end{array}$ & $\begin{array}{l}\text { Infarct } \\
\text { present }\end{array}$ & $\begin{array}{c}\text { Site of } \\
\text { occlusion } \dagger\end{array}$ & Complication \\
\hline 1 & Right coronary & + & Dissection & + & Proximal & None \\
\hline 2 & Left anterior descending & & Dissection & + & Distal & None \\
\hline 3 & Right coronary & & Dissection & + & Distal & None \\
\hline 4 & Left anterior descending & - & Branch occlusion & + & Diagonal left anterior descending artery & None \\
\hline 5 & Left circumflex & - & Dissection & + & Proximal & Ventricular fibrillation \\
\hline 6 & Left circumflex & - & Embolism & + & Posterior descending coronary artery & Bradycardia \\
\hline 7 & Left anterior descending & $-\cdot$ & Spasm & - & Diagonal left anterior descending artery & Ventricular fibrillation \\
\hline 8 & Left circumflex & ++ & Dissection & - & Proximal & None \\
\hline 9 & Right coronary & ++ & Dissection & - & Segment 2 & None \\
\hline 10 & Left anterior descending & - & Thrombus & + & Proximal & Death \\
\hline 11 & Right coronary & - & Unknown & + & Proximal & Death $\ddagger$ \\
\hline
\end{tabular}

good collateral blood flow (cases 1, 8, and 9), the small size of the occluded artery (cases 4 and 5), or closure of a distal arterial segment (cases 2 and 3). In one patient (case 6) coronary occlusion was associated with the visible migration of thrombus into the distal posterior descending coronary artery, and medical management was considered to be the only appropriate treatment. In another patient (case 7) occlusion was caused by sustained coronary spasm of a diagonal left anterior descending artery. This was relieved after 45 minutes by repeated intracoronary injections of glyceryl trinitrate. None of the nine patients who developed coronary occlusion at coronary angioplasty died, but late coronary occlusion and death occurred in two patients (cases 10 and 11) (see below).

\section{DEATHS}

Five deaths $(0.9 \%)$ occurred in patients treated by coronary angioplasty. Two of these deaths were not caused by coronary occlusion. One was related to bilateral, peripheral vascular embolisation at insertion of the arterial sheath, and the other occurred in a 55 year old man who received thrombolytic treatment for myocardial infarction. Coronary angioplasty was performed on a left main stem stenosis as an emergency procedure, but, although the procedure was technically successful, cardiogenic shock persisted and he died three days later. Postmortem examination confirmed extensive myocardial infarction. The artery at the site of angioplasty was widely patent.

In three patients death was related to coronary occlusion. The first patient was a 68 year old man with unstable angina. Cardiac catheterisation showed multivessel disease with mild impairment of left ventricular function. Acute occlusion occurred eight hours after initially successful coronary angioplasty of the left anterior descending artery. Occlusion was followed by rapid haemodynamic collapse and death within 15 minutes. Necropsy confirmed thrombotic arterial occlusion.

The second patient was a 72 year old woman with unstable angina at rest. Single vessel coronary disease was present with a proximal, eccentric, stenosis of $90 \%$ in a tortuous, dominant right coronary artery. Cardiac function was normal. This patient refused revascularisation surgery, which was the preferred treatment. Angioplasty was complicated by arterial dissection. Coronary occlusion developed nine hours after coronary angioplasty. Myocardial infarction and cardiac failure followed, leading to death within 24 hours.

The third patient was a 55 year old woman with progressively worsening angina. Multivessel coronary disease was present with normal cardiac function. Coronary angioplasty of the proximal left anterior descending artery was complicated by acute closure of the vessel associated with severe hypotension and an atrioventricular conduction block of two to one. The occlusive lesion was successfully redilated. Recurrence of the chest pain with haemodynamic deterioration and death occurred 10 days later. Consent for a postmortem examination was refused.

\section{Discussion}

"An experienced cardiovascular surgical team should be available within the institution for emergency surgery for all angioplasty procedures."' This statement $\dot{\vec{\omega}}$ from the Task Force on Assessment of Diagnostic of and Therapeutic Cardiovascular Procedures of the American College of Cardiology and American Heart Association has highlighted an important issue for centres in the United Kingdom performing coronary angioplasty. Many centres, including ours, do not have immediate access to on site cardiac surgery. If the recommendations of the task force were to be fully implemented these centres would have to abandon their angioplasty programmes. As yet there have been no formal guidelines on this issue in the United Kingdom. We believe that a policy statement along the lines of the recommendations of the American task force would not be an appropriate course of action in the United Kingdom. This view is based on our experience with 540 coronary angioplasties performed without on site cardiac surgery. Several points can be made from a review of these data.

Three deaths occurred that were related to the development of acute coronary occlusion at or shortly after angioplasty. The absence of on site surgery did not influence the outcome in any case. Death occurred either rapidly (first patient) before a surgical team could be mobilised, even if it was available on site, or late (in the second patient at 24 hours and the third patient at 10 days), allowing time for an operation to be performed had this been decided. The rapid 9 deterioration seen in the first patient shows the hazard $N$ of performing coronary angioplasty in a patient with severe multivessel disease, irrespective of the nature of surgical cover available.

Transfer between the angioplasty and surgical centres can be accomplished safely. Twelve patients required urgent coronary bypass surgery in our series, 11 after acute coronary occlusion and one after the guide wire fragmented in the lumen of the left anterior $\mathbb{Q}$ descending coronary artery (case 12, table II). That coronary occlusion occurred in major vessels is shown by the development of serious cardiac arrhythmias in five patients and severe systemic hypotension in one. After stabilisation of rhythm and haemodynamic disturbances all patients were safely transferred the $2.4 \mathrm{~km}$ to the surgical unit.

The transfer of patients between hospitals after complications at coronary angioplasty inevitably creates a delay before revascularisation can be per- $\rightleftharpoons$ formed. This additional delay is considered to be unacceptable by the American task force.' Our experience in Belfast clearly shows that an appreciable delay does occur between the onset of coronary 
occlusion and revascularisation surgery but that the main component of this delay is not the transfer time between hospitals. Factors that delayed transfer to the surgical unit included attempts to redilate the occlusive lesion in the catheterisation laboratory, the wait for an ambulance to arrive, and the journey time between the hospitals. We believe that these factors would be common to any similar centre in the United Kingdom. The short distance to the surgical centre and the transfer of the patient directly to the cardiac operating theatre, however, may facilitate a more rapid transfer than would be possible in other centres-for example, in places where traffic is congested and surgical cover has not been arranged before angioplasty. Transfer to the surgical centre was usually accomplished within 60 minutes after coronary occlusion, yet the mean delay before revascularisation was 268 minutes (range 180 to 390 minutes). The delay for complicated procedures performed within the Royal Victoria Hospital, where on site surgical cover is available, was virtually identical at 273 minutes (range 108 to 420 minutes). Though any delay between acute coronary occlusion and revascularisation surgery is undesirable, these results show that transferring a patient to the surgical centre does not necessarily increase the delay before revascularisation. The main component of the delay in Belfast was the wait for a cardiac operating theatre to become free. This is probably true for many other centres in the United Kingdom where cardiac surgeons, faced with lengthy waiting lists, continue with their normal surgical caseload while angioplasty is being carried out.

If the recommendations of the task force were adopted and angioplasty programmes abandoned, what would be the implications for management of patients considered suitable for coronary angioplasty? The mortality from coronary angioplasty in the Belfast City Hospital is low at $0.9 \%$ and is comparable with that reported by others. ${ }^{2}$ If coronary angioplasty were abandoned some 150 patients would be added to the waiting list for surgical revascularisation in Northern Ireland each year. As the current waiting list is of the order of 800 patients, a delay of two or more years often occurs before revascularisation surgery is performed. Patients waiting for surgery remain at risk of cardiac events such as myocardial infarction and even death. Studies in patients with symptoms have shown that if only one of the three major coronary arteries has a lesion of $>50 \%$ severity the annual mortality will be approximately $2 \%,{ }^{3}$ particularly when the proximal left anterior descending artery is diseased. ${ }^{+}$This was the commonest lesion in our series. Adding to this the mortality from the surgical procedure itself $(2 \cdot 4 \%$ in the 8991 patients of the coronary artery surgery study registry ${ }^{5}$ ), an increase rather than a decrease in mortality will result from discontinuing procedures simply because facilities for immediate on site surgery are not available.

If angioplasty is performed in a hospital without on site surgical facilities careful selection of cases is required to exclude patients who are at high risk of serious haemodynamic consequences in the event of acute coronary occlusion. If patients do not fall into this high risk group we believe that it is safe to perform angioplasty in a centre without on site surgical cover, provided that this is available at a nearby centre. In the event of coronary occlusion patients who require revascularisation surgery (about one third in our series) can be safely transferred to the surgical unit.

We thank Mr H O'Kane (consultant cardiac surgeon) and Dr M Khan (consultant cardiologist) at the Royal Victoria Hospital for their help in gathering the data.

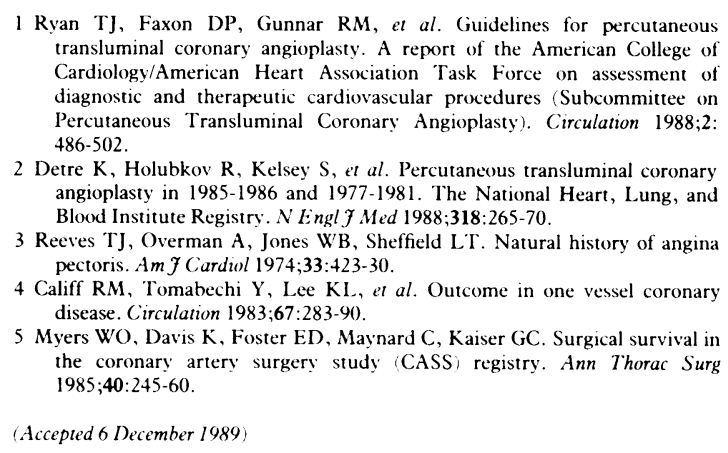

I Ryan TJ, Faxon DP, Gunnar RM, et al. Guidelines for percutaneous transluminal coronary angioplasty. A report of the American College of Cardiology/American Heart Association Task Force on assessment of diagnostic and therapeutic cardiovascular procedures (Subcommittee on Percutaneous Transluminal Coronary Angioplasty). Circulation 1988;2. 486-502.

2 Detre K, Holubkov R, Kelsey S, et al. Percutaneous transluminal coronary angioplasty in 1985-1986 and 1977-1981. The National Heart, Lung, and Blood Institute Registry. N Engl f Med 1988;318:265-70.

3 Reeves TJ, Overman A, Jones WB, Sheffield LT. Natural history of angina pectoris. Am f Cardiol 1974;33:423-30.

4 Califf RM, Tomabechi Y, Lee KL, et al. Outcome in one vessel coronary disease. Circulation 1983;67:283-90.

5 Myers WO, Davis K, Foster ED, Maynard C, Kaiser GC. Surgical survival in the coronary artery surgery study CASS) registry. Ann Thorac Surg $1985 ; 40: 245-60$.

(Accepted 6 December 1989

Department of Thoracic Medicine, Brompton

Hospital, London SW3 6HP

$\mathrm{M}$ W Elliott, $\mathrm{MRCP}$, research fellow

M H Steven, MCSP, senior physiotherapist

G D Phillips, MRCP, senior registrar

M A Branthwaite, FRCP, consultant

Correspondence to: $\mathrm{Dr}$ Branthwaite.

BrMed f 1990;300:358-60

\title{
Non-invasive mechanical ventilation for acute respiratory failure
}

\author{
M W Elliott, M H Steven, G D Phillips, M A Branthwaite
}

\begin{abstract}
The value of mechanical ventilation using intermittent positive pressure ventilation delivered noninvasively by nasal mask was assessed in six patients with life threatening exacerbations of chronic respiratory disease. Median (range) arterial oxygen and carbon dioxide tensions were $4.4(3.5-7.2) \mathrm{kPa}$ and $8.7(5.5-10.9) \mathrm{kPa}$ respectively, with four patients breathing air and two controlled concentrations of oxygen. The arterial oxygen tension increased with mechanical ventilation to a median (range) of 8.7 $(8 \cdot 0-12 \cdot 6) \mathrm{kPa}$ and the carbon dioxide tension fell to $8 \cdot 2(6 \cdot 5-9 \cdot 2) \mathrm{kPa}$. Four patients discharged after a median of 10 (8-17) days in hospital were well five to 22 months later. One died at four days of worsening sputum retention and another after five weeks using the ventilator for 12-16 hours each day while awaiting heart-lung transplantation.

This technique of mechanical ventilation avoids endotracheal intubation and can be used intermittently. Hypercapnic respiratory failure can be relieved in patients with either restrictive or
\end{abstract}

obstructive lung disease in whom controlled oxygen treatment results in unacceptable hypercapnia. Respiratory assistance can be tailored to individual need and undertaken without conventional intensive care facilities.

\section{Introduction}

Intermittent positive pressure ventilation delivered non-invasively through a well fitting nasal mask can control nocturnal hypoventilation and relieve chronic respiratory failure. ${ }^{12}$ The ventilator delivers a predetermined tidal volume either in response to the initiation of a spontaneous breath by the patient or automatically. The concept has developed from the widely used technique of nasal continuous positive airway pressure ${ }^{3}$ in which patients are breathing spontaneously. By contrast, gas flow in and out of the lungs during nasal intermittent positive pressure ventilation depends primarily on the ventilator. We report the use of nasal intermittent positive pressure ventilation in six patients with acute, life 